\title{
Prenatal diagnosis of Duchenne muscular dystrophy by DNA analysis
}

\author{
JOHN M OLD AND KAY E DAVIES \\ From the Nuffield Department of Clinical Medicine, John Radcliffe Hospital, Oxford OX3 9DU.
}

SUMMARY Linkage studies have been carried out in 20 families segregating for Duchenne muscular dystrophy and eight prenatal diagnoses performed, including six first trimester diagnoses and one twin pregnancy. The results of the restriction fragment length polymorphism (RFLP) analysis suggest that not all the possible RFLPs need to be used and a strategy for carrier detection studies is proposed.

At least 11 DNA probes have been isolated from the short arm of the human $\mathrm{X}$ chromosome and their positions mapped with respect to the locus of the muscular dystrophy gene in band $\cdot X p 21.1^{-5}$ Each of these probes has a useful restriction fragment length polymorphism (RFLP) which can be used for the prenatal diagnosis of Duchenne muscular dystrophy (DMD) by linkage analysis. This is carried out by studying the appropriate family members for the presence of heterozygous RFLPs and using the closest informative polymorphic markers flanking the DMD mutation. The disadvantage of this approach is that there are now too many DNA probes for it to be technically feasible to study all the RFLPs at the same time. The approach usually adopted is to study the closest markers first and then try the other probes in sequence until informative markers are found. This is very time consuming and cannot be done for a family requesting a first trimester diagnosis which has not been studied beforehand. A further disadvantage with this approach is that if the closest markers are uninformative, the chance of a single recombination event occurring becomes very significant as markers are used further away from the $D M D$ locus.

Recently DNA probes have become available which have been isolated from the $\mathrm{Xp} 21$ region itself (pERT87-1, 87-8, 87-15, and the probe XJ1.1) and, in theory, these probes ought to be the most useful for prenatal diagnosis. ${ }^{4}$ However, studies using these probes by several groups of workers have shown that there is still a significant chance of recombination between them and the $D M D$ locus. ${ }^{67} \mathrm{~A}$ second problem with these probes is that their positions

Received for publication I Junc I986.

Revised version accepted for publication 15 July 1986. relative to the $D M D$ locus have not been resolved and therefore they cannot be used as flanking markers in combination with any of the other DNA probes. Therefore, at present, it is not straightforward to decide which are the best probes to use for carrier detection and prenatal diagnosis, especially in cases in which the RFLP analyses have to be carried out within two to three weeks in time for a first trimester prenatal diagnosis to be performed if required.

In this paper we present the data from a study of 20 families for carrier status or prenatal diagnosis of Duchenne muscular dystrophy and outline our strategy for such cases in the future. We have performed eight prenatal diagnoses for DMD by RFLP analysis to date and the results are described here.

\section{Materials and methods}

DNA was isolated from blood or fetal samples as previously described. ${ }^{8}$ DNA was digested to completion with the appropriate enzymes and electrophoresed in $0.8 \%$ agarose gels. The gels were blotted onto nylon filters (Hybond N, Amersham International plc) and hybridised to the various probes labelled by either nick translation or hexanucleotide priming. The filters were washed in $3 \mathrm{X} \mathrm{SSC}$ at $65^{\circ} \mathrm{C}$ and autoradiographed for one to five days at $-70^{\circ} \mathrm{C}$. For rehybridisation, filters were cleared of hybridised probe by washing for 30 minutes in $5 \mathrm{mmol} / \mathrm{l}$ Tris $\mathrm{HCl} \mathrm{pH} 7.5$ at $75^{\circ} \mathrm{C}$.

\section{Results}

DNA samples from 20 families were analysed for carrier detection and the possibility of using one or 
more polymorphic markers for prenatal diagnosis. For the first five families seven probes were used: RC8, D2, 99-6, C7, 754, OTC, and L1.28. Informative polymorphisms flanking the $D M D$ locus which could be used for prenatal diagnosis were found in four out of the five family studies. The most useful probe was D2 (three out of four families) and the least informative one was RC8 (one out of five). In families 3 and 4, 99-6 was not used because the closer probe $\mathrm{C} 7$ was informative, and in family 5 the studies were left incomplete because pERT87-8 was found to be informative.

Families 6 to 20 were analysed with just the two closest flanking markers to the $D M D$ locus, $C 7$ and 754, and the two pERT87 probes, 87-1 (Bst NI and XmnI RFLPs) and 87-8 (TaqI and BstXI RFLPs). The loci $C 7$ and 754 were informative for prenatal diagnosis in eight of 20 and seven of 20 families respectively. However, they could only be used together as flanking markers in four of 20 families. Because of various technical reasons, results were not

TABLE 1 Haplotypes (pERT87-1 and 87-8)

\begin{tabular}{lllllll}
\hline & BstNI & XmnI & TaqI & BstXI & No & Frequency \\
& $87-1$ & $87-1$ & $87-8$ & $87-8$ & & \\
\hline I & - & - & + & - & 24 & 0.69 \\
II & + & + & - & + & 7 & 0.20 \\
III & - & + & - & + & 3 & 0.08 \\
IV & + & - & + & + & 1 & 0.03 \\
\hline
\end{tabular}

$+=$ presence of restriction enzyme site.

$-=$ absence of restriction enzyme site. obtained for all of the pERT RFLPs. The marker pERT87-1 was used in 13 families and the BstNI RFLP could be used for prenatal diagnosis in two families $(15 \%)$ and the XmnI RFLP in five $(38 \%)$. Similarly, the TaqI RFLP with pERT87-8 was informative for prenatal diagnosis in four out of nine families (44\%) and the BstXI RFLP in six out of 11 families $(54 \%)$. No deletions for either probe were found in any of the 15 families.

During these studies with the pERT87-1 and 87-8 probes it was noted that many $\mathrm{X}$ chromosomes had the same haplotype for these four RFLPs, suggesting there is linkage disequilibrium between them. Only four haplotypes out of the possible 16 were observed (table 1), showing the non-random association of the four polymorphic restriction sites. One particular haplotype was found to be very common compared to the other three, occurring on 24 out of $35 \mathrm{X}$ chromosomes. Nearly $40 \%$ of the females studied were homozygous for this haplotype, making none of the pERT87 polymorphisms informative. This was the case in families 15,16 , and 20 in table 2 and also most probably in families $10,14,17$, and 18 . Interestingly, when a female is heterozygous for the most common haplotype and the second most common haplotype, all four polymorphic sites are heterozygous and therefore informative for carrier detection or prenatal diagnosis.

Eight prenatal diagnoses of DMD have been carried out at Oxford to date. These are listed in table 3. The first two diagnoses were performed on DNA from cultured amniotic fluid cells and the

TABLE 2 DNA probes which were informative for prenatal diagnosis of Duchenne muscular dystrophy.

\begin{tabular}{|c|c|c|c|c|c|c|c|}
\hline Family & $R C 8$ & $D 2$ & $99-6$ & $C 7$ & 754 & OTC & $L 1.28$ \\
\hline 1 & + & - & - & - & + & - & - \\
\hline 2 & - & + & - & - & - & - & + \\
\hline 3 & - & + & & + & - & + & + \\
\hline 4 & - & + & & + & + & + & + \\
\hline \multirow[t]{2}{*}{5} & - & & & - & - & + & - \\
\hline & $C 7$ & 754 & $\begin{array}{l}87-1 \\
\text { BstNI }\end{array}$ & $\begin{array}{l}87-1 \\
X m n I\end{array}$ & $\begin{array}{l}87-8 \\
\text { TaqI }\end{array}$ & $\begin{array}{l}87-8 \\
\text { Bst } X I\end{array}$ & $\begin{array}{l}87-15 \\
X m n I\end{array}$ \\
\hline 6 & + & + & & & & + & \\
\hline 7 & - & - & & & + & + & \\
\hline 8 & + & + & - & - & + & & \\
\hline 9 & - & - & - & + & & + & \\
\hline $\begin{array}{l}10 \\
11\end{array}$ & $\overline{+}$ & $\overline{-}$ & - & - & - & + & \\
\hline 12 & $\stackrel{+}{-}$ & - & $\bar{t}$ & $\begin{array}{l}+ \\
+\end{array}$ & & + & \\
\hline 13 & + & - & + & + & + & + & + \\
\hline 14 & - & - & - & - & - & & \\
\hline 15 & + & + & - & - & - & - & - \\
\hline 16 & - & - & - & - & - & - & + \\
\hline 17 & - & - & - & - & & - & \\
\hline 18 & + & - & - & - & & - & \\
\hline $\begin{array}{l}19 \\
20\end{array}$ & - & $\begin{array}{l}+ \\
+\end{array}$ & - & + & + & + & \\
\hline
\end{tabular}

$+=$ marker was informative

$-=$ marker was uninformative 
TABLE 3 Prenatal diagnoses of DMD carried out at Oxford.

\begin{tabular}{llllll}
\hline Case & DNA source & Prohes used & Scit & Diagnosis & Outcomc \\
\hline 1 & Amniocytes & 754.782 & $\mathrm{M}$ & Affected & Terminated \\
2 & Amnicoytes & 87.8 & $\mathrm{M}$ & Affected & Terminated \\
3 & CVS & $87-8$ & $\mathrm{M}$ & Uninformative & Terminated \\
4 & CVS & $754 . \mathrm{C7}$ & $\mathrm{M}$ & Affected & Terminated \\
5 & CVS twin I & $87-1.878$ & $\mathrm{M}$ & Normal & Continuing \\
& CVS twin 2 & 871.878 & $\mathrm{~F}$ & Normal & Continuing \\
6 & CVS & 871.878 & $\mathrm{M}$ & Affected & Terminated \\
7 & CVS & 87.1 .878 & $\mathrm{M}$ & Affected & Terminated \\
\hline
\end{tabular}

remainder on DNA from chorionic villi samples (CVS). Two cases were diagnosed by using a pair of flanking markers: 754 and 782 in one case and 754 and $C 7$ in the second. The other six cases were diagnosed by linkage to pERT87 RFLPs, quoting a recombination frequency of $5 \%$. In one case (case 3 ) a diagnosis could not be made because the mother turned out to be homozygous for the common pERT87 haplotype and was also uninformative for the markers $C 7$ and 754 . However, this subject has since been found to be heterozygous for the pERT87$15 \mathrm{XmnI}$ RFLP and so prenatal diagnosis is possible for her in the future. Only one out of seven male fetuses was diagnosed as unaffected in a continuing $\frac{\mathbb{D}}{\mathbb{D}}$ pregnancy and therefore this is the only one in which : the diagnosis that has been made will be subject to $\overrightarrow{\vec{N}}$ verification.

The results of the prenatal diagnosis of DMD in the twin pregnancy are shown in the figure. The $\frac{\bar{\sigma}}{\overline{0}}$ mother was at risk because of a high serum creatine $\mathbb{\nabla}$ kinase level and a family study with the BstXI RFLP 응 showed that she had inherited a different RFLP, the $s$ $2.2 \mathrm{~kb}$ allele, from that inherited by her normal $\vec{O}$ brother, the $4.4 \mathrm{~kb}$ allele. A chorionic villus sample $\overrightarrow{-}$ was taken from each of the twin fetuses and analysed $\vec{\omega}$ for the BstXI RFLP. The $4.4 \mathrm{~kb}$ allele was observed in both fetal DNA samples indicating that they had 0 both inherited the normal $\mathrm{X}$ chromosome from their i mother. There was some doubt concerning the sex of 0 the second twin because karyotype analysis of $\mathcal{G}$ cultured chorionic villi cells gave both a male and on female phenotype. Therefore, the filter containing the 은 Bst XI digested DNA (prepared directly from un- cultured villi cells) was rehybridised with a repeat DNA sequence probe specific for the Y chromosome. The probe only hybridised to the DNA from one of 3

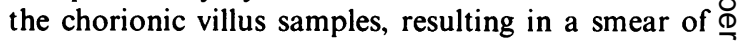
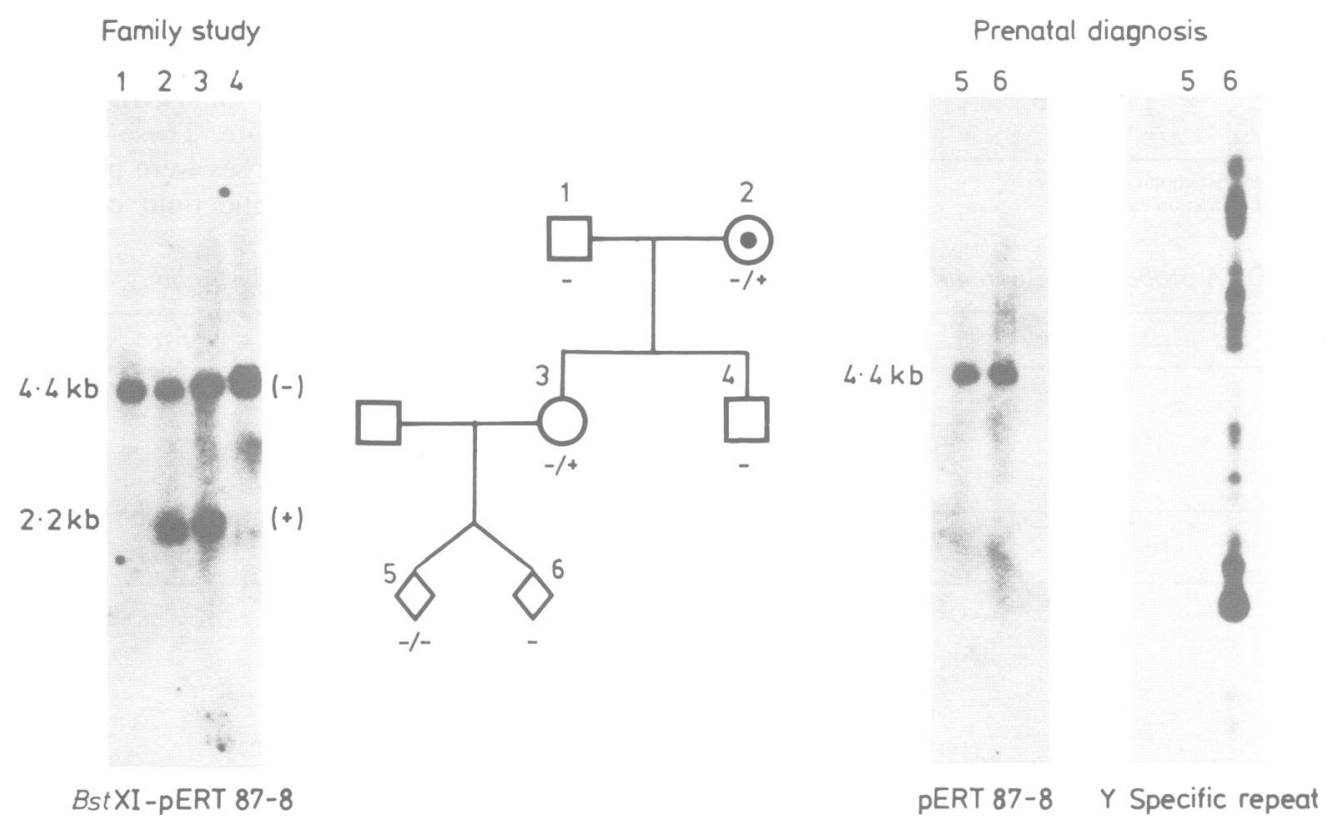

FIGURE Prenatal diagnosis of DMD in a twin pregnancy by linkage analysis. DNA was digested with Bst XI and hybridised to the probe pERT87-1. An autoradiograph shows the results of the family study (subjects 1,2, 3, 4) and the analysis of DNA $\$$ from a chorionic villus sample from each twin fetus (subjects 5 and 6 ). The result of rehybridising the Bst XI digested fetal DNA samples to a $Y$ chromosome specific repeat DNA sequence probe is also shown.

$\odot=$ female, DMD carrier. The $4.4 \mathrm{kh}$ allele is represented by a minus sign and the $2 \cdot 2 \mathrm{~kb}$ allele is represented by a plus sign. 
bands containing the $\mathrm{Y}$ specific repeat sequence and confirming that the chorionic villus samples came from different fetuses, one male and one female.

\section{Discussion}

There are now at least 15 DNA probes that can be used for carrier status studies and prenatal diagnosis of DMD by RFLP linkage analysis, and this number is bound to increase as more probes are isolated from the Xp21 region in the search for the DMD gene. Clearly a strategy is necessary for using these probes for family studies, especially when an answer may have to be obtained in two to three weeks, the time between referral of an unstudied family and the last possible date for a chorionic villus sampling. Under our laboratory conditions, this gives us time to study only five or six RFLPs at most. Therefore, once the pERT87 probes became available we stopped using all flanking probes except the two closest markers, C7 and 754. Apart from the OTC locus, the other markers are $15 \mathrm{cM}$ or more from the $D M D$ locus and therefore not as useful as the markers $\mathrm{C} 7$ and 754, because there is a $30 \%$ or greater chance of DNA recombination affecting a prenatal diagnosis. The markers 754 and $C 7$ are both thought to be about 10 cM from the $D M D$ locus; therefore, used together, a diagnosis is $99 \%$ reliable and is more accurate than the Xp21 probes, all of which have an estimated $5 \%$ recombination frequency with DMD. ${ }^{7}$

Only two of the four Xp21 probes have been used extensively on our families to date: pERT87-1 and pERT 87-8. Because of the observed non-radom association of the four RFLPs, the two probes were often informative for carrier detection in a family study, but having shown a subject to be a carrier they could not be used for prenatal diagnosis, as the subject concerned was homozygous for the common haplotype. However, recent studies with pERT87-15 (XmnI) and XJ1.1 (TaqI) have shown that these polymorphisms can be informative when all four RFLPs for pERT87-1 and pERT87-8 are uninformative. Therefore, it seems necessary to use all four $\mathrm{Xp} 21$ probes in a family study to obtain the maximum chance of finding a useful polymorphism. Fortunately, our results show that it is not necessary to analyse all four pERT87-1 and pERT87-8 RFLPs. The most common situation in informative subjects was the heterozygous combination of haplotypes 1 and 2 (table 1) resulting in all four sites being informative. The second most common situation was the pairing of haplotypes 1 and 3 which resulted in all the RFLPs being informative except BstNI. This explains why BstNI was the least useful RFLP in the families presented in table 2. Therefore, analysis of only one RFLP for each probe is necessary: $X m n I$ for pERT87-1 and possibly TaqI for pERT87-8 as this enzyme is much cheaper than BstXI.

In our laboratory the maximum number of DNA digestions that can be carried out over a two week period for a family study is about six. Thus, our current approach is to analyse each family for six RFLPs: C7 (EcoRV), 754 (Pstl) pERT87-1 (XmnI), pERT87-8 (Taql), pERT87-15 (XmnI), and XJ1.1 (TaqI). These can be analysed sequentially by rehybridising filters if no urgency is required.

We would like to thank The Muscular Dystrophy Group of Great Britain, The Muscular Dystrophy Association of America, and The Medical Research Council for generous support. We are also grateful to Carol Heath and Alison Finch for their technical assistance and to Rachel Kitt for careful typing of the manuscript.

\section{References}

I Aldridge J. Kunkel L. Bruns G. Lalande M. Tantravahi U. Latt S. A strategy for construction of highly polymorphic DNA haplotypes in specific human chromosomal regions: application to linkage analysis of $\mathrm{X}$ chromosome specific diseases such as Duchenne muscular dystrophy. Ital J Neurol Sci 1984:3:39 46.

2 Bakker E. Hofker MH. Goor N. "l al. Prenatal diagnosis and carrier detection of Duchenne muscular dystrophy with closely linked RFLPs. Lancet 1985;i:655 8.

3 Davies KE. Molecular genetics of the human X chromosome. $J$ Med Gienet 1985:22:243 9

+ Monaco AP. Bertelson CJ. Middlesworth W. el al. Detection of deletions spanning the Duchenne muscular dystrophy locus using a tightly linked DNA segment. Nature 1985:316:842 5

5 Ray PN. Belfall B. Duff C. 't al. Cloning of the breakpoint of an $\mathrm{X}: 21$ translocation associated with Duchenne muscular dystrophy. Naturc 1985:318:672 5

- Goodfellow P, Davies KE, Ropers HH. Report of the committee on the genetic constitution of the $\mathrm{X}$ and $\mathrm{Y}$ chromosome. Human Gene Mapping 8. Cytogenet Cell Genet 1985;40:296-352.

${ }^{7}$ Kunkel LM, Hejtmancik JF, Caskey CT, et al. Analysis of deletions in DNA from patients with Becker and Duchenne muscular dystrophy. Nature 1986;322:73-7.

8 Old JM. Fetal DNA analysis. In: Davies KE, ed. Analysis of human genetic diseases. Oxford: IRL Press, 1986: 1-15.

Correspondence and requests for reprints to $\mathrm{Dr} \mathrm{J} \mathrm{M}$ Old, Nuffield Department of Clinical Medicine, John Radcliffe Hospital, Oxford OX3 9DU. 